\title{
Characterization of Microstructure and Mechanical Properties of CuCr Alloy Produced by Stir Casting
}

\author{
Sami Abualnoun Ajeel, Rabiha S. Yaseen, Asaad Kadhim Eqal \\ Department of Production Engineering \& Metallurgy, University of Technology \\ asaadka77@gmail.com
}

\begin{abstract}
The relatively low mechanical properties of pure copper at low and high temperature made it very limited applications. The mechanical properties of the copper can be improved by adding a small amount of elements such as $\mathrm{Cr}$. This work consists of four $\mathrm{CuCr}$ alloy castings $(0.3,0.8$, 1.2 and $1.5 \%$ ) by using the stir casting method in an argon atmosphere. Then, the heat treatment was done for these alloys which included solution treatment and aging. Heat treatment was treated at $980^{\circ} \mathrm{C}$ for 1 hour, then waterquenching, followed by an aging treatment at $480^{\circ} \mathrm{C}$ for 2.4 and 6 hours. The Optical Microscopy and the Scanning Electron Microscopy (SEM) with (EDS) were used to study the microscopic structure of the produced alloys. The results showed that the mechanical properties of copper increased with increasing chromium content. The microstructure of the castings consist of the dendiritic structure, columinar and segregation. It has been also indicated that after heat treatment and aging, the microstructure changed to fine grains and the clusters disappeared. XRD showed a $\alpha-\mathrm{Cu}$ phase and a small amount of $\mathrm{CrO}_{2}$ in microstructures. The highest value of hardness and the ultimate tensile were 101 $\mathrm{Hv}$ and $239.12 \mathrm{MPa}$, respectively. They were achieved at $1.5 \mathrm{wt} \%$ addition of $\mathrm{Cr}$ at $480^{\circ} \mathrm{C}$ and $4 \mathrm{hrs}$ aging.
\end{abstract}

Keywords: copper based alloy, dendrite, homogenization, heat treatment, Mechanical properties; Microstructure; Phase transitions

Paper History: (Received: 26-6-2018, Accepted: 11-112018)

\section{Introduction}

Copper-based alloys have many applications in industry such as railway, connectors, contact wires, lead frame, automobile radiators, pipes, valves and heat exchangers[1, 2]. An important property that makes the copper-based alloys meet the industrial demands is the excellent mechanical strength. Copper-chrome alloys are examples of the precipitat hardening strengthening.This is done by precipitate of fine and uniform particle-dispersion in copper matrix [3, 4]. In addition, chrome have low solubility in copper matrix in room temparature. The casting process is the most economical method for obtaining a part of any desired composition, with any size from a few millimeters to large scale even in case of mass production and complicated parts. Casting processes have become one of the important techniques which are used to produce several types of alloy especially, in the case of mass production and complicated parts [5]. The production of copper chromium alloys with optimum functional properties is difficult and is associated with technological problems. hese problems occur during the melting and liquid metal preparation process [6]. However, the affinity of copper to oxygen carries the greatest difficulty where the low activity of copper results in the formation of soluble oxides. But, the presence of chromium forms $\mathrm{Cr}_{2} \mathrm{O}_{3}$, which is insoluble and difficult to be eliminated from the bath [7, 8, and 9]. The production of $\mathrm{Cu}-\mathrm{Cr}$ alloys has been the subject of many investigations $[10,11,12]$. For instance, Sayyed Mohammad et al. studied the effect of water-cooled copper mold on the microstructures and hardness for a for $98.88 \mathrm{Cu}$ $-1.12 \mathrm{Cr} \% \mathrm{wt}$ alloy cast. There is a copper matrix saturated with chromium, spherical precipitates of chromium separated from the liquid phase during cooling before the initiation of solidification, and a eutectic phase in grain boundary areas. The results show that the hardness of samples increases from $\mathrm{Hv} 113$ to $\mathrm{Hv} 161$ after annealing in a salt bath at $450^{\circ} \mathrm{C}$ for a holding time of $16 \mathrm{~h}$ due to coherent precipitates with the diameter of $11 \mathrm{~nm}$ are detectable in the samples before and after the age-hardening stage [11]. Similarly, Lijun Peng et al. investigated the phase transformation of a $\mathrm{Cu}-0.71 \mathrm{wt} \% \mathrm{Cr}$ alloy during the aging process at $450{ }^{\circ} \mathrm{C}$. The precipitation sequence of $\mathrm{Cu}-$ $0.71 \mathrm{wt} \% \mathrm{Cr}$ aged at $450{ }^{\circ} \mathrm{C}$ is supersaturated solid solution (fcc Cr-rich phase), fcc $\mathrm{Cr}$ phase, order fcc $\mathrm{Cr}$ phase and bcc $\mathrm{Cr}$ phase. When the specimen is aged aging for 1 for 24 $\mathrm{h}$, both fcc and bcc precipitates exist in the matrix simultaneously. The strengthening effect of Cr-rich phase precipitated in aging at $450^{\circ} \mathrm{C}$ for $8 \mathrm{~h}$ is calculated to be 146 $\mathrm{MPa}$ on the basic of the Orowan strengthening mechanism, which is in quite an accordance with the experimental data (144.5 MPa) [12]. Researches of the $\mathrm{Cu}-\mathrm{Cr}$ alloy have focused on the study conductivity of copper chrome more than mechanical properties. In the present work, the stir casting process and solution heat treatment with the various addition of $\mathrm{Cr}$ content are adapted to study the influence on microstructure and mechanical properties that suitable in the mechanical application. 


\section{Experimental Procedure}

\section{Material}

The purity of copper and chromium that used in this study is $99.78 \%$ and $99.4 \%$ respectively. The particle size of the chromium powder used is about $75 \mu \mathrm{m}$. They analyzed by ICP -AES in IBN SINA FACTORY as tabulated in Table 1. The raw materials were sectioned to $20 \times 20 \times 20 \mathrm{~mm}$ in order to the melting materials in stir casting is much easier.

\section{Tools and Equipments}

In this work, stir casting method is used. It is consist of induction furnace, graphite crucible and drill. Graphite impellerwith a speed of 600 RPM is used to mixing metal melt as shown in Figure 1(a, b, d, and e). Cast iron mold is with two holes diameter $10 \mathrm{~mm}$ and $16 \mathrm{~mm}$ is shown in Figure1(c). Optical Microscope (OM) observation, Vickers microhardness test of the specimens were measured at $300 \mathrm{~g}$ of load using a Digital Micro Vickers Hardness Tester TH714 in Production Engineering and Metallurgy Department/ University of Technology. Hardness at three different points per one specimen was measured randomly, and the mean hardness value was calculated. XRD using a Shimadzu $6000 \mathrm{X}$-ray diffraction target $\mathrm{CuK} \alpha 1$ radiation with $2 \theta$ angle was covered from 15 to 120 degree. Scanning electron microscopy (SEM) was used to investigate microstructures. Energy dispersive spectroscopy (EDS) was applied to identify elements and other microstructural features.

\section{Casting and Molding}

The melting of material was done in the pouring temperature of $1230{ }^{\circ} \mathrm{C}$ [10]. The process started with the preparation of the charge containing required quantities of different elements of $\mathrm{Cu}$ and $\mathrm{Cr}$. Stir casting method with argon atmosphere was adopted to producing the experimental samples. Two types of stirring technique were used. These types were mechanical stir and magnetic field that produced from induction furnace. This is used to increase the wettability between $\mathrm{Cr}$ particles and melted metal. The casting mold is preheated to $(100-150){ }^{\circ} \mathrm{C}$ before pouring to minimize the casting defects such as shrinkage cavities and refines the grain size is obtained [11]. The raw materials was calculated by using the accurate balance as a percentage of weight after and before casting as shown in Table 2. The difference in percent value is due to lose during casting. Fluxes are usually based on borax, providing covering in addition to its ability to dissolve and collect this objectionable oxide shell. It also leads to increase the fluidity of the liquid metal, which allows floating of oxides and other impurities on the surface of copper melt that causes the slags [12] The use of graphite or charcoal is necessary to avoid gaseous reactions that contained moisture could motivate with sulfur or hydrogen [13].This alloy near to chrome-copper alloy standard C81500 [14] Infrared thermometer was used to measure the molten metal temperature. Heraeus HANAU furnace in Production Engineering and Metallurgy Department/ University of Technology was used to done the solution treatment and aging with argon atmosphere as shown in Figure $2(a, b)$.

\section{Heat Treatment}

The heat treatment that used in this work, was solution treatment at $980^{\circ} \mathrm{C}$ for 1 hour and then quenched water. Aging at $480 \mathrm{C}$ for at different time (2, 4, and 6) hours were applied. These processes are done for all casts homogenization and enhancement in the microstructure were obtained.

\section{Sample Preparation}

The ingots are produced by stirr casting methods as shown in Figure 3. The cast diamension was $16 \mathrm{~mm}$ diameter and length $120 \mathrm{~mm}$ as rods. These casts were cutted to specimens with dimension $5 \mathrm{~mm}$ length and $16 \mathrm{~mm}$ diameter. The tensile test samples diamensions were prepared by using turning machine according to ASTM E8M to identify mechanical properties as shown in the Figure 4( $a$ and $b)$. The specimens taken from each alloy was hot mounted and grinding by electric disk rotary device using different grades of emery papers $120,320,500,1000,2000$ and 3000. These grinded specimens are polished with cloth diamond lubricant using the polishing device. The specimens after polishing are etched by Keller reagent $(5 \mathrm{~g} \mathrm{FeCl} 3,95 \%$ methanol, $5 \mathrm{~mL} \mathrm{HCl})$ in order to reveal the microstructure and microhardness[15].

\section{Results and Discussion}

\section{Microstructure of $\mathrm{Cu}-\mathrm{Cr}$ Alloys}

Figures 5(a, b, c, and f) indicate the microstructure features of cast $\mathrm{Cu}-\mathrm{Cr}$ alloys was studies by the optical micrographs. It showed the microstructure of alloys cast consists of dendrites $\alpha$ solid solution face-center cubic lattice and eutectic of $\mathrm{Cr}$. These phases demonstrate a substantial microstructural difference with increased of $\mathrm{Cr}$ additions. The dendritic arm spacing increases with increasing solidification time. The dendrite size became relatively fine when the chromium content increased from 0.3 to $1.5 \mathrm{wt} \%$ as shown in Figure 5 (c and d). It is observed during cast solidification the elongated primary grains, $\alpha$ solid solution dendrite and the fine lamellar $\mathrm{Cu}-$ $\mathrm{CrO}_{2}$ eutectic as the intermetallic compound in the grain boundaries. These results will enhance the mechanical properties of $\mathrm{Cu}-\mathrm{Cr}$ alloys. 


\section{Solution Treatment and Microhardness of Alloys}

The equiaxed grains are clearly observed in all samples due to the reduction in segregation and dendritic. This reduction is obtained by solution treatment at $1 \mathrm{hr}$ and aging at $480{ }^{\circ} \mathrm{C}$, as shown in Figure 6(a,b,c, and f). It is considered an evidence for the formation of coherent precipitates of $\mathrm{Cr}$ in the $\mathrm{Cu}$ matrix. In addition, the $\mathrm{Cr}$ atom has a slower diffusion rate in the $\mathrm{Cu}$ lattice at a lower temperature. It has resulted from distortion lattice that caused by coherency between the matrix and coherent precipitated particles. The effect of $\mathrm{Cr}$ element on the hardness of the copper alloys and aging time is shown in Figure 6 . The best hardness value is observed at the aging time of $4 \mathrm{hrs}$. it is obvious that the hardness of the samples increases during the $\mathrm{Cr}$ content increased. The hardness of the sample in $4 \mathrm{hrs}$ increases from $76 \mathrm{Hv}$ to $101 \mathrm{Hv}$ when the chrome content increase from 0.3 to $1.5 \mathrm{wt} \%$. From Figure 7, the hardness increases rapidly for all samples at the aging time of 4 hours. Then, it decreases with 6 hours of aging time. This is because of the overegging and coarsening.

Figure 8 (a,b and c) shows the SEM images with EDX analysis of $\mathrm{Cu}-\mathrm{Cr}$ alloy. In this figure, the microstructures of specimens are precipitates of $\mathrm{Cr}$ that formed with aging or that contains more dissolved $\mathrm{Cr}$ as solid solution in the copper matrix. As expected from EDX analysis of $(0.3$ and $0.8) \% \mathrm{Cr}$ content shows that the matrix is $\alpha \mathrm{Cu}$ phase, while the dark region is a $\mathrm{Cr}$-rich phase as the intermetallic compound. These particles formed inside the $\mathrm{Cu}$ matrix that grows by effect of aging[11]. The intermetallic phase of the cast is demonstrated using XRD CuK $\alpha 1$ radiation as shown in Figure 9. The major strong peaks of $\alpha \mathrm{Cu}$ are identified. The other phase associated with the presence of $\alpha \mathrm{Cu}$ phase is $\mathrm{CrCuO}_{2}$ phase. The intensity of the lines of the $\alpha$ phase relative to the intensity of the lines of the $\mathrm{CrCuO}_{2}$ phase will decrease due to change in total composition and decreases the amount of $\mathrm{Cu}$ relative to the amount of $\mathrm{Cr}$ $[18,19]$.

\section{Tensile Test}

Figure 10 represents the stress-strain diagram for all samples that solution treatment at $980{ }^{\circ} \mathrm{C}$ for $1 \mathrm{~h}$ and aging time at $480{ }^{\circ} \mathrm{C}$ for 4 hours. It explains a significant increase in ultimate tensile and yield strengths with increase $\mathrm{Cr}$ content. In this figure, when the $\mathrm{Cr}$ content increased from 0.3 to $1.5 \mathrm{wt} \%$ the ultimate tensile and yield strengths change from $175 \mathrm{Mpa}$ to $239.12 \mathrm{Mpa}$ and $38.97 \mathrm{Mpa}$ to $110.32 \mathrm{Mpa}$ respectively. In addition was observed the increase in hardness from $48.67 \mathrm{Hv}$ to $101.3 \mathrm{Hv}$ with an increase in $\mathrm{Cr}$ content as shown in Figure (11). The high strength and hardness accompanied by an increase in strain. These are attributed to the formation of nano-scaled $\mathrm{Cr}$ precipitates in the $\mathrm{Cu}$ matrix during the aging process. This is because of the extremely low solubility of $\mathrm{Cr}$ in $\mathrm{Cu}$ at room temperature and the interactions of grain boundary strengthening and strain hardening that occurs during the tensile test [20]. From Figure (11) the decrease in elongation from $50.7 \%$ to $28.5 \%$ was observed with an increase in $\mathrm{Cr}$ content. This is due to the precipitation hardening that result from low solubility of solute atoms in the $\mathrm{Cu}$ matrix. It is important here to mention that avoid coarse precipitation in solidification or fragment and redistributing the alloying contents is a key factor to the improvement of the mechanical properties of the alloy [21].

\section{Conclusions}

Stir casting methods through it two type of stirring technique were used. The effect of $\mathrm{Cr}$ content and solution treatment on the mechanical properties of the copper alloy was investigated. The result showed that changes in microstructure were noticed. It also indicated that precipitation strengthening occurred owing to the increase in $\mathrm{Cr}$ content. Reduction and the change of dendrites microstructure to equiaxed grains that were formed after solution treatment and aging that indication for recrystallization. The $\mathrm{Cr}$ content increased hardness values of samples due to the coherent precipitates formed during cooling at room temperature and in aging treatment. It is found that the formed precipitates are very effective at the increase of the hardness of the material.

\section{Acknowledgment:}

This work was supported by University of Technology, Production Engineering \& Metallurgy Department, which is gratefully acknowledged

\section{References}

\section{Paper in a journal:}

[1]. Zhilyaev, A. Morozova, "Wear resistance and electroconductivity in a $\mathrm{Cu}-0.3 \mathrm{Cr}-0.5 \mathrm{Zr}$ alloy processed by ECAP" J. Mater Sci, pp. 31, 2017.

[2]. Li-Jun Penga, Hao-fengXie,"Effect of Heat Treatment on the Microstructure of $\mathrm{Cu}-\mathrm{Cr}-\mathrm{Zr}$ Alloy", Key Engineering Materials, Vol. 727, pp. 1662-9795, 2016.

[3]. Steven J Zinkle,"Applicability of copper alloys for DEMO high heat flux Components" Physica Scripta ,Vol.167, pp10, 2016.

[4]. Dobatkin,"High strength and good electrical conductivity in $\mathrm{Cu}-\mathrm{Cr}$ alloys processed by severe plastic deformation" Materials Letters, Vol.153 pp.59, 2015.

[5]. Smith W. J., "Copper and its Alloys" Proceeding of an International Conference Organized By the Institute of Metals Held in Amsterdam, pp. 32, 1970. 
[6]. RZADKOSZ, M. KRANC, "Refining Processes In the Copper Casting Technology" METABK Vol. 54(1), pp. 259-262, 2015.

[7]. St.Rzadkosza,M. Kranc," Research on Technology of Alloyed Copper Casting" archives of foundry engineering Vol. 14, pp. 79-84, 2014.

[8]. Milan. Jovanovic, "Copper Alloys With Improved Properties: Standard Ingot Metallurgy" Vs. Powder Metallurgy, Metal. Mater. Eng. Vol 20 (3), pp. 207216, 2014.

[9]. Shangina J. Gubicza E. Dodony,"Improvement of strength and conductivity in $\mathrm{Cu}$-alloys with the application of high pressure torsion and subsequent heat-treatments "J. Mater Sci. Ultra-fine grained Materials, pp.4, 2014.

[10]. Que, J.H.Lee, H.M.Jung, J.H.Shin, S.Z.Han, K.J.Euh, "Microstructure Evolution in $\mathrm{Cu}-1.54 \mathrm{Wt} \% \mathrm{Cr}$ Alloy During Directional Solidification" Journal of Crystal Growth 362, pp. 58-61, 2013.

[11]. Seyyed Mohammd Hossein Hejazi , "A Cu-Cr alloy with nano and microscale $\mathrm{Cr}$ particles produced in a water-cooled copper mold" International Journal of Minerals, Metallurgy and Materials Volume 17, pp. 629, 2010.

[12]. Sponsored by KBM,"Properties and Applications of copper Chromium $(\mathrm{CuCr})$ Master Alloy from "KBM, pp. 7, 2014.

[13]. Stephen M. Copley "Heat Treating ASM Handbook" Volume 4, ASM Handbook Committee pp 1356, 1991.

[14]. Sami A. Ajeel, Ahmed N. Ibrahiem, Abdul Salam A. Fadhil, "Study on Improvement of Casting Conditions for Some Aluminum Bronze Alloys" Eng. \& Technology, Vol.25, No.6,.pp.2, 2007.

[15]. Que a,n, J.H.Lee, "Microstructure evolution in $\mathrm{Cu}-$ 1.54 wt $\% \mathrm{Cr}$ alloy during directional solidification" Journal of Crystal Growth Vol.362 pp.58-61, 2013.

[16]. ChengdongXia , Wan Zhang, "High strength and high electrical conductivity $\mathrm{Cu}-\mathrm{Cr}$ system alloys manufactured by hot rolling-quenching process and thermomechanical treatments" Materials Science and Engineering A, Vol. 538, pp.295-301, 2012.

[17]. Stephen M. Copley "copper and copper alloy ASM Handbook" ASM Handbook Committee pp 92, 1991.

[18]. IBRAHIM SAĞLAM, "Effect of ageing treatment on wear properties and electrical conductivity of $\mathrm{Cu}-\mathrm{Cr}-$ Zr alloy" Bull. Mater. Sci., Vol. 34, No. 7, pp. 14651470, 2011.

[19]. CULLITY, "Elements of X-Ray Diffraction" Second Edition, Department of Metallurgical Engineering and Materials Science University of Nôtre Dame, pp. 370400, 1978.

[20]. Mohammad Baghani, Mahmood Aliofkhazraei, and Mehdi Askari, " $\mathrm{Cu}-\mathrm{Zn}-\mathrm{Al} 2 \mathrm{O} 3$ nanocomposites: study of microstructure, corrosion, and wear" International Journal of Minerals, Metallurgy and Materials Volume 24, Number 4, pp. 462, 2017.

[21]. Olofinjana ,"Properties of rapidly solidified binary copper alloys" Materials Letters 31, pp 87-92, 1997.

[22]. Zhao Mei,Lin Guobiao, "Analysis of precipitation in a $\mathrm{Cu}-\mathrm{Cr}-\mathrm{Zr}$ alloy" Research \& Development Vol.5 No.4.pp.7, 2008.

Table : the analytical chemical composition of the pure $\mathrm{Cu}$ and $\mathrm{Cr}$ powder

\begin{tabular}{|l|l|l|l|l|l|l|}
\hline Alloy & $\mathrm{Cu}$ & $\mathrm{Cr}$ & $\mathrm{Ag}$ & $\mathrm{Fe}$ & $\mathrm{P}$ & $\mathrm{Pb}$ \\
\hline Pure $\mathrm{Cu}$ & 99.78 & - & 0.127 & 0.05 & 0.046 & 0.001 \\
\hline $\mathrm{Cr}$ powder & - & 99.40 & - & 0.4 & - & 0.11 \\
\hline
\end{tabular}
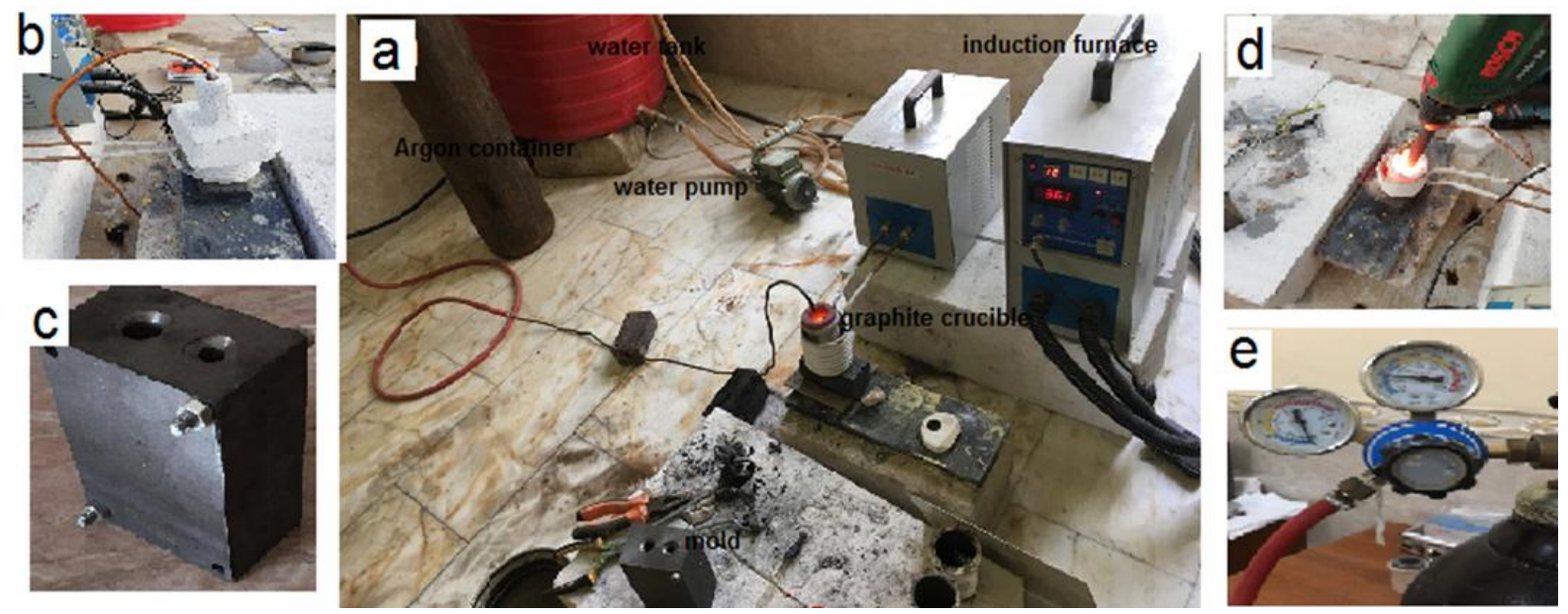
Figure 1: showed (a) Stir casting system, (b) Cup to inert gas, (c) Cast iron mold (d) Stirring with graphite crucible, (e) Argon container.

Table 2: the percent of $\mathrm{Cr}$ addition after and before casting of the alloys

\begin{tabular}{|c|c|}
\hline Percent of Cr added wt $\%$ & Percent analysis after casting wt $\%$ \\
\hline 0.6 & 0.3 \\
\hline 1 & 0.8 \\
\hline 1.5 & 1.3 \\
\hline 1.8 & 1.5 \\
\hline
\end{tabular}
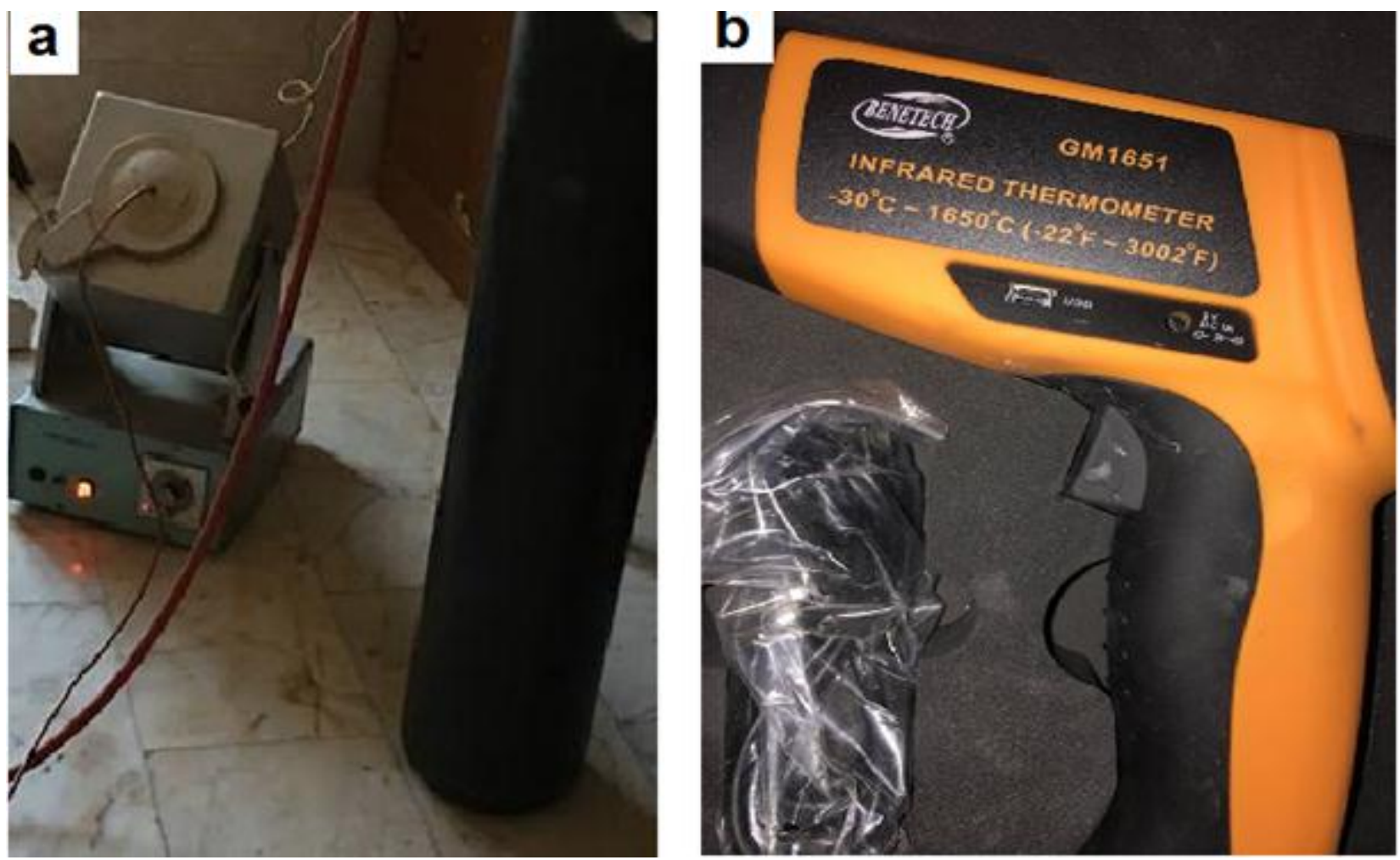

Figure 2: shows (a) solution treatment furnace, (b) Thermometer infrared. 


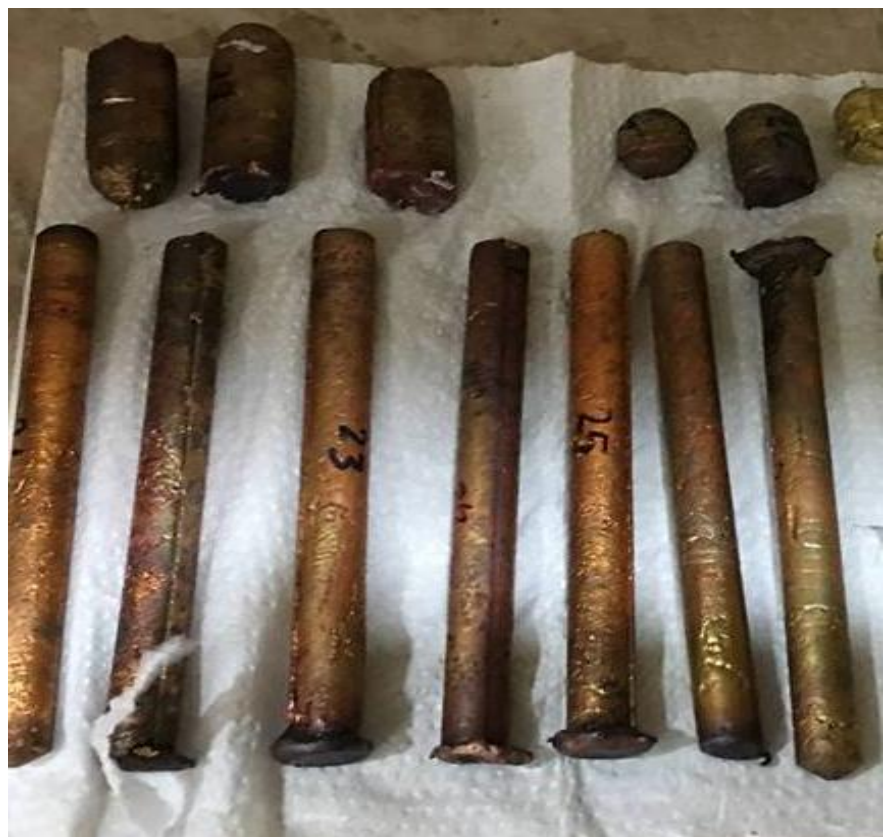

Figure 3: shown the rod casts ingot that produced by stirr casting

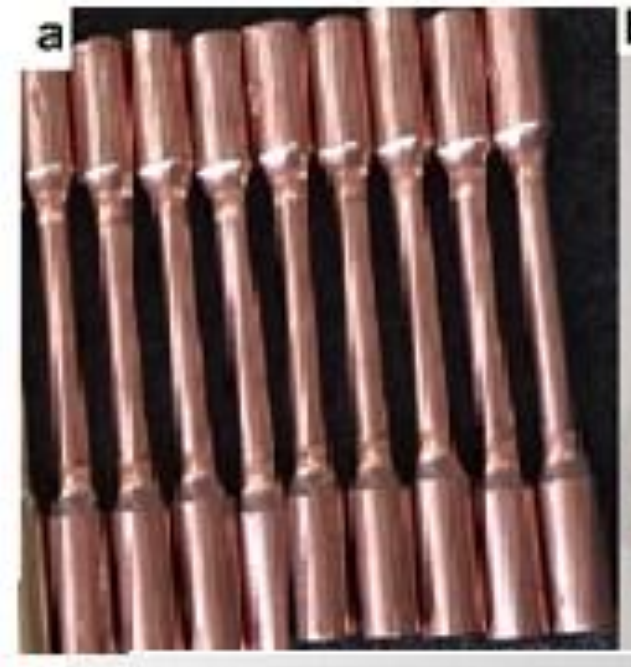

C

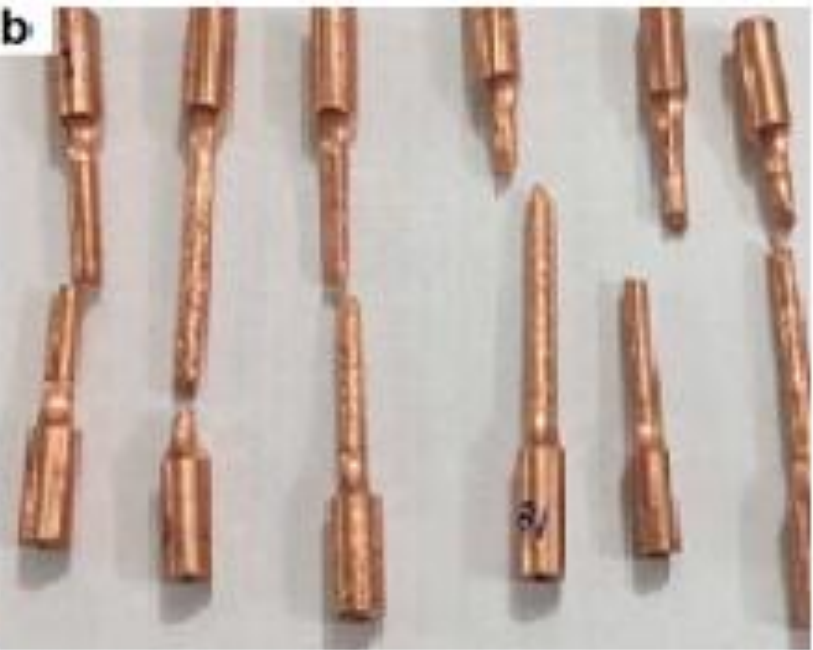

\section{$54 \mathrm{~mm}$}

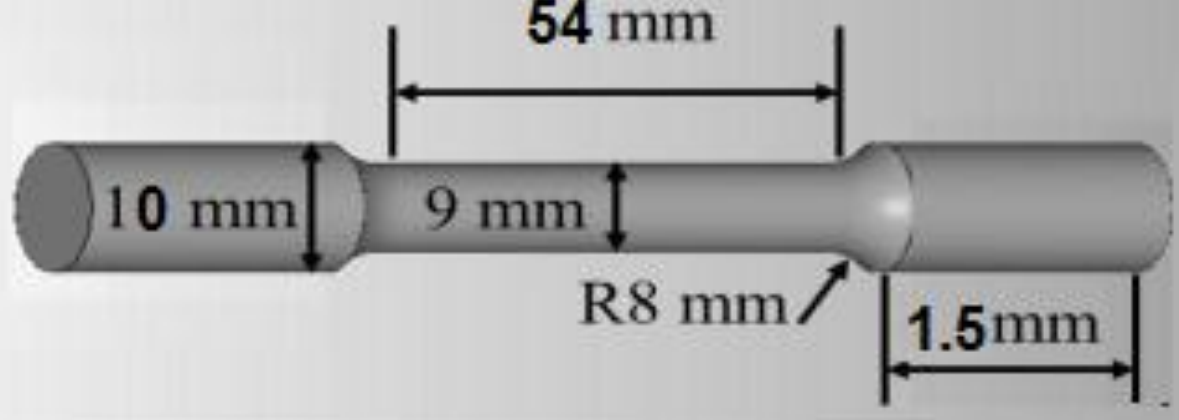

Figure 4: shown tensile test samples (a) before test, (b) after test, (c) standard of tensile test. 

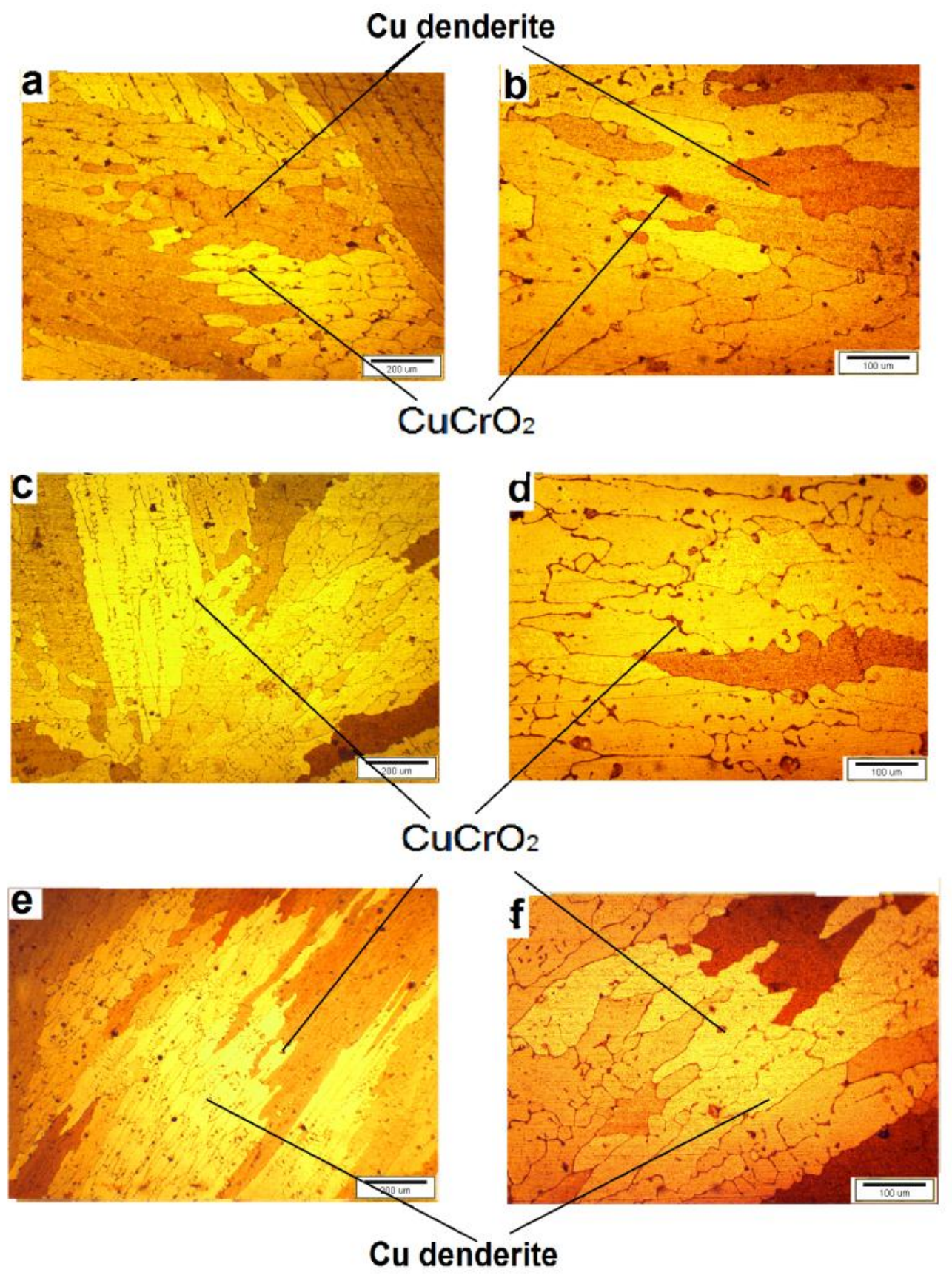

Figure 5: Optical microscope of cast $\mathrm{CuCr}$ alloy identified as $\mathrm{Cu}$ dendrite of $0.8 \mathrm{Cr}$ wt.\% (a,b), $1.3 \mathrm{Cr}$ wt.\% (c,d), and $1.5 \mathrm{Cr}$ wt.\% (e,f) at magnification $100 \mathrm{X}$ and $200 \mathrm{X}$. 

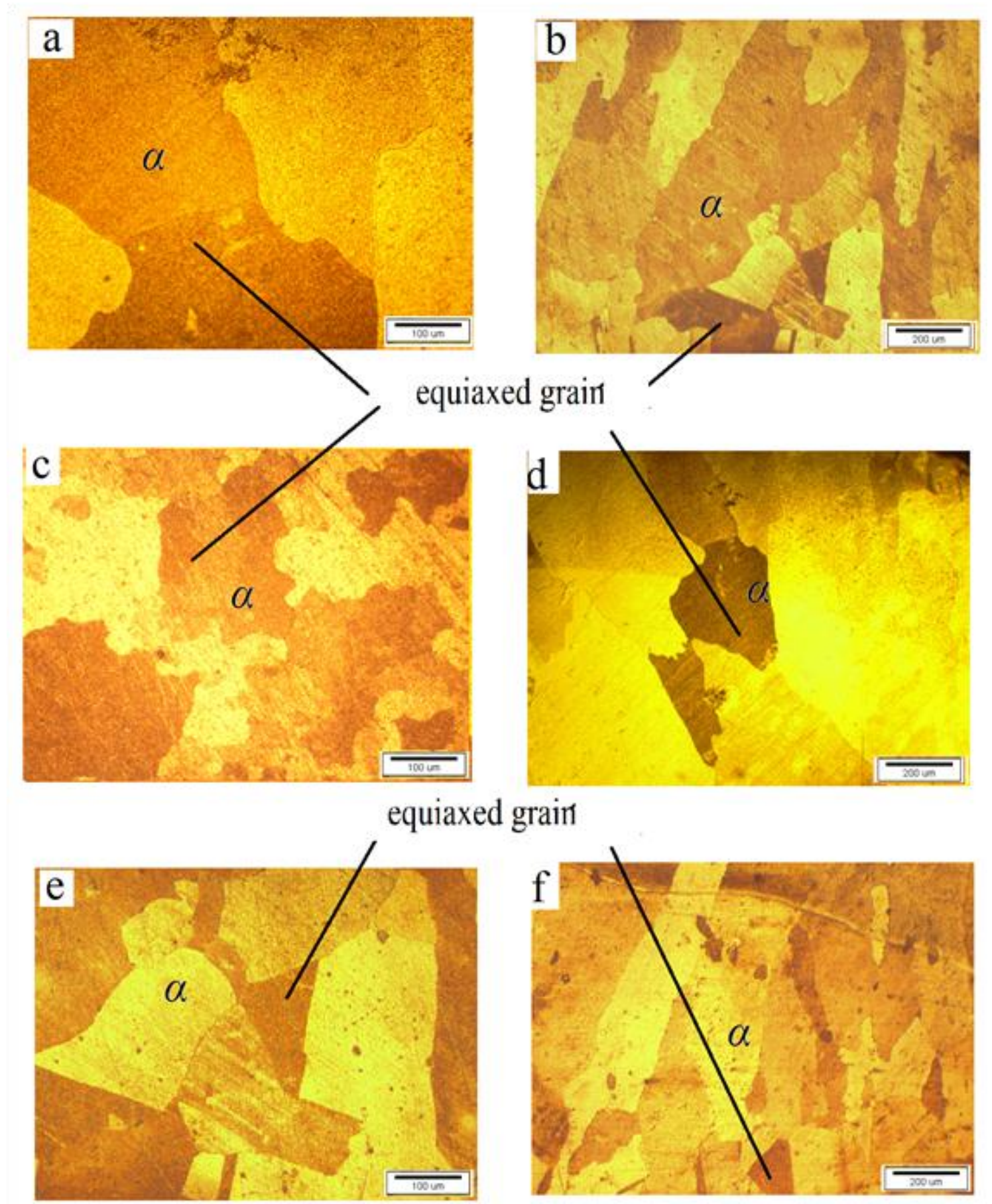

Figure 6: Optical microscope of cast $\mathrm{CuCr}$ alloy as equiaxed grains of $0.8 \mathrm{Cr}$ wt.\% (a,b), $1.3 \mathrm{Cr}$ wt.\% (c,d), and $1.5 \mathrm{Cr}$ wt. $\%(e, f)$ at magnification 100X and 200X 


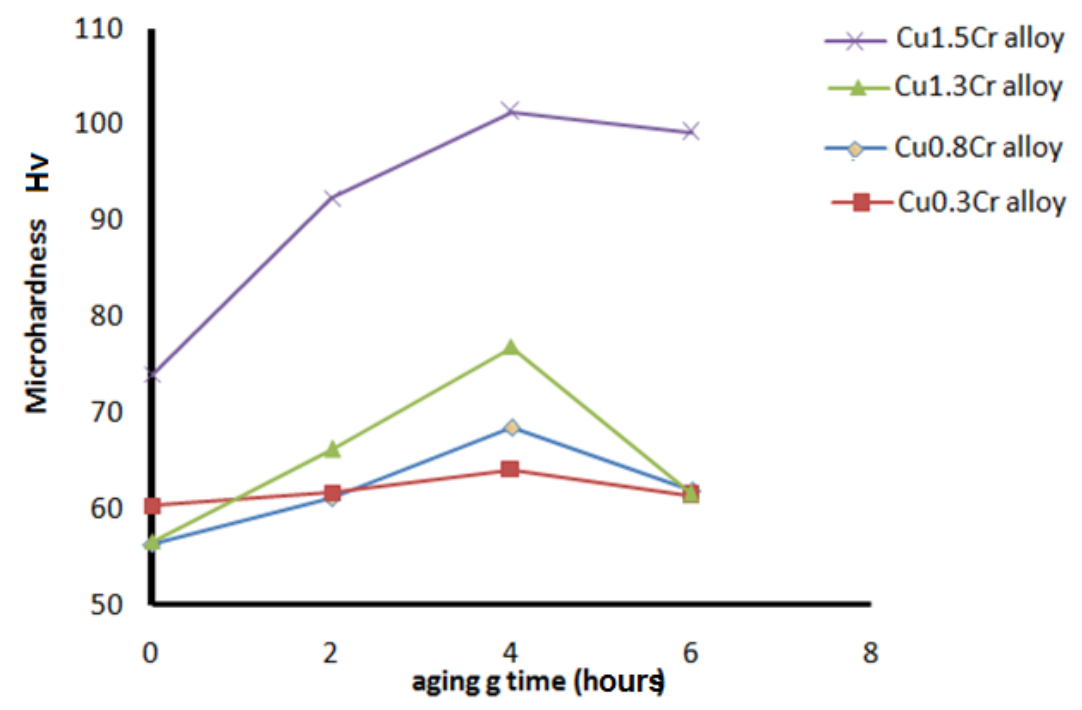

Figure 7: Microhardness measurements of $\mathrm{Cu} \mathrm{Cr}$ alloy that solution treatment in $980{ }^{\circ} \mathrm{C}$ for $1 \mathrm{~h}$ at different aging time at $480{ }^{\circ} \mathrm{C}$.
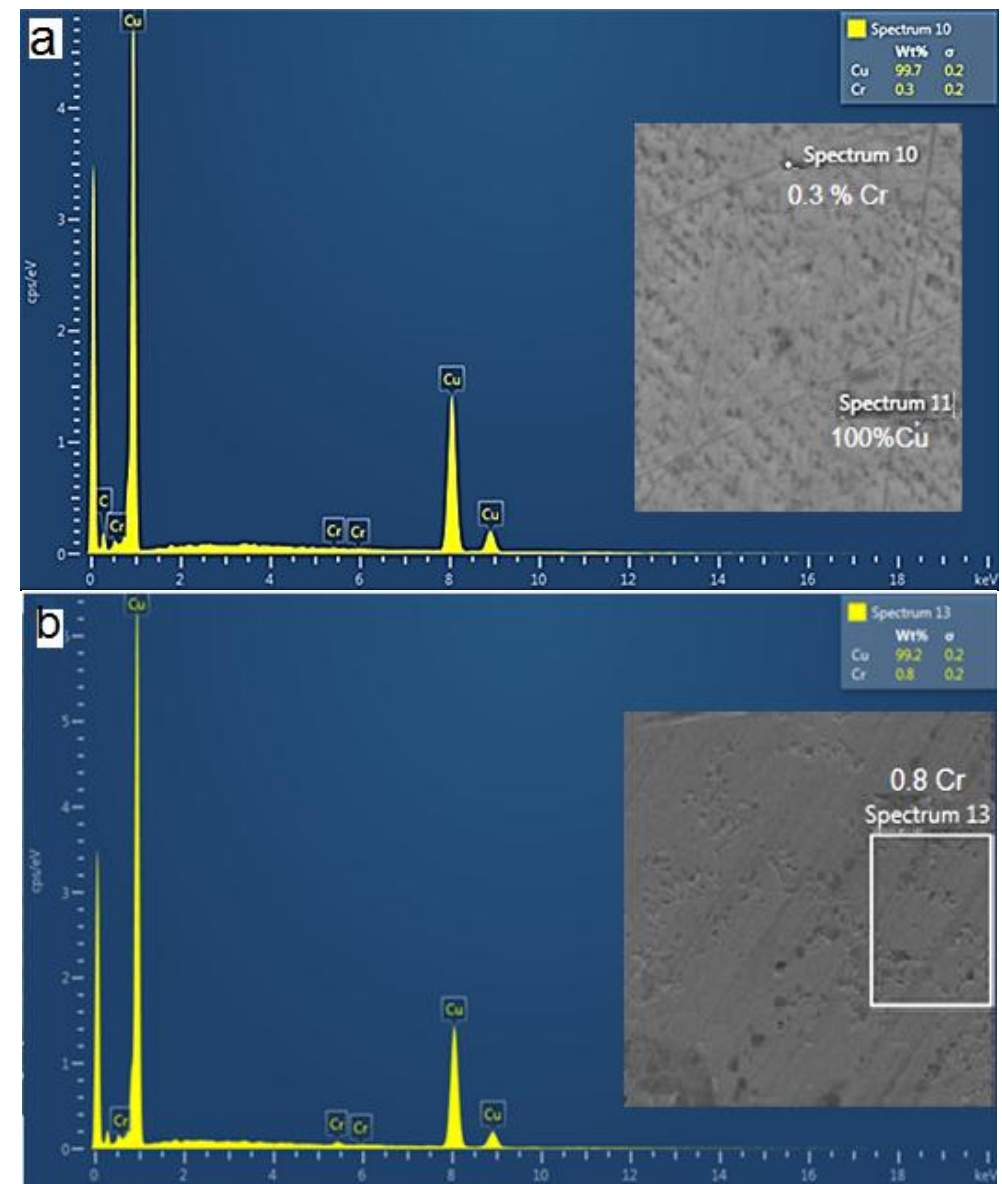

Figure 8: SEM with EDX analysis shown the gray phases are identified as $\mathrm{Cu}$ dendrite and the dark region is phase content $\mathrm{Cr}, \mathrm{Cu}-0.3 \mathrm{Cr}$ alloy (a), $\mathrm{Cu}-0.8 \mathrm{Cr}$ (b). 


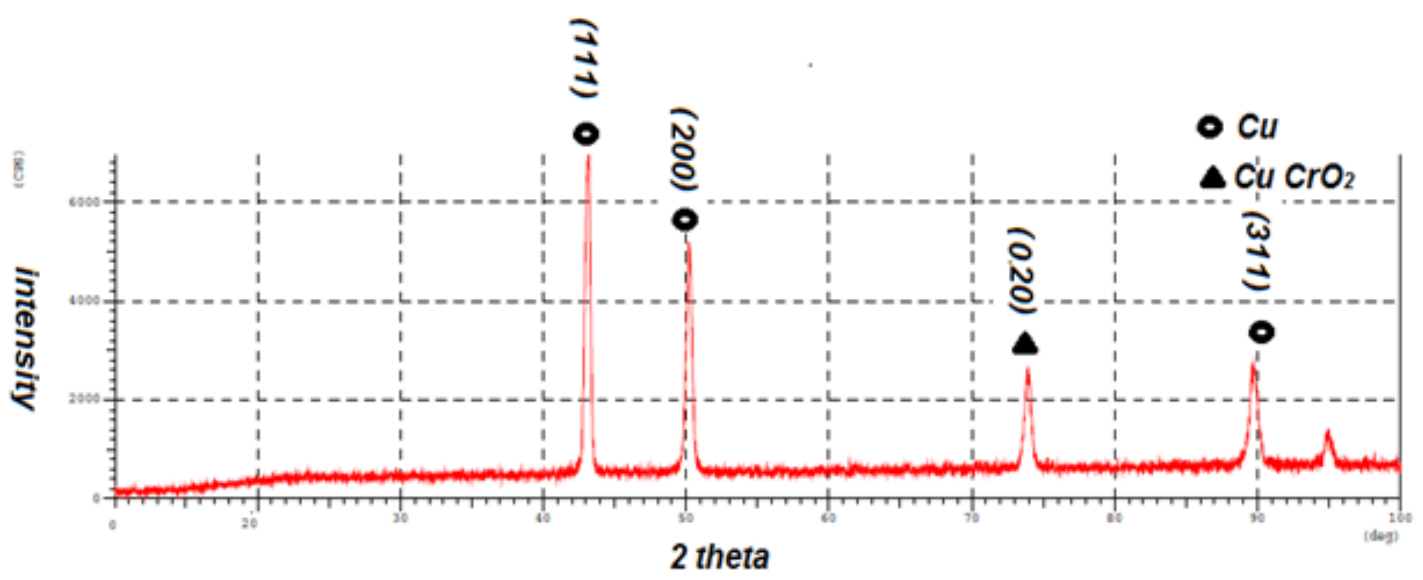

Figure 9: shown $\mathrm{XRD}$ using $\mathrm{Cu} \mathrm{K} \alpha$ radiation $\mathrm{Cu}$ peaks of $\mathrm{Cu} \mathrm{Cr}$ alloy

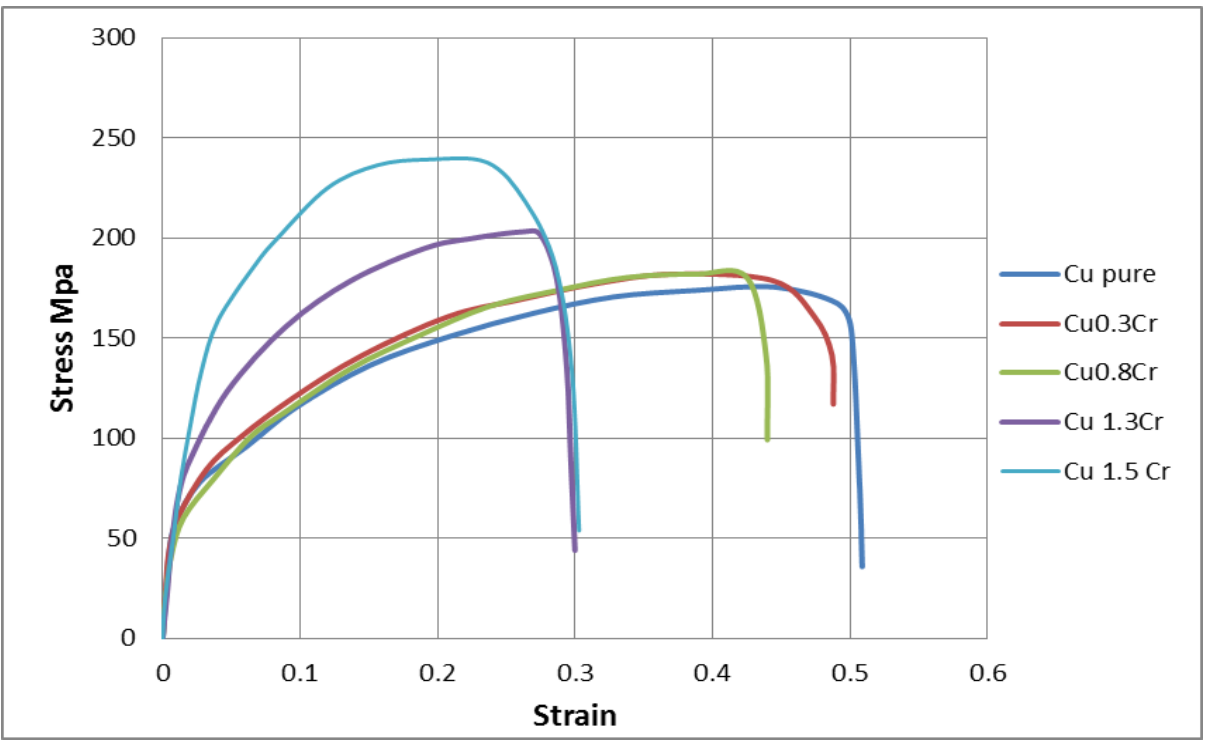

Figure 10: Stress - Strain diagram of $\mathrm{Cu} C r$ alloy that solution treatment in $980 \mathrm{C}$ for $1 \mathrm{~h}$ and aging at $480{ }^{\circ} \mathrm{C}$ for $4 \mathrm{~h}$.

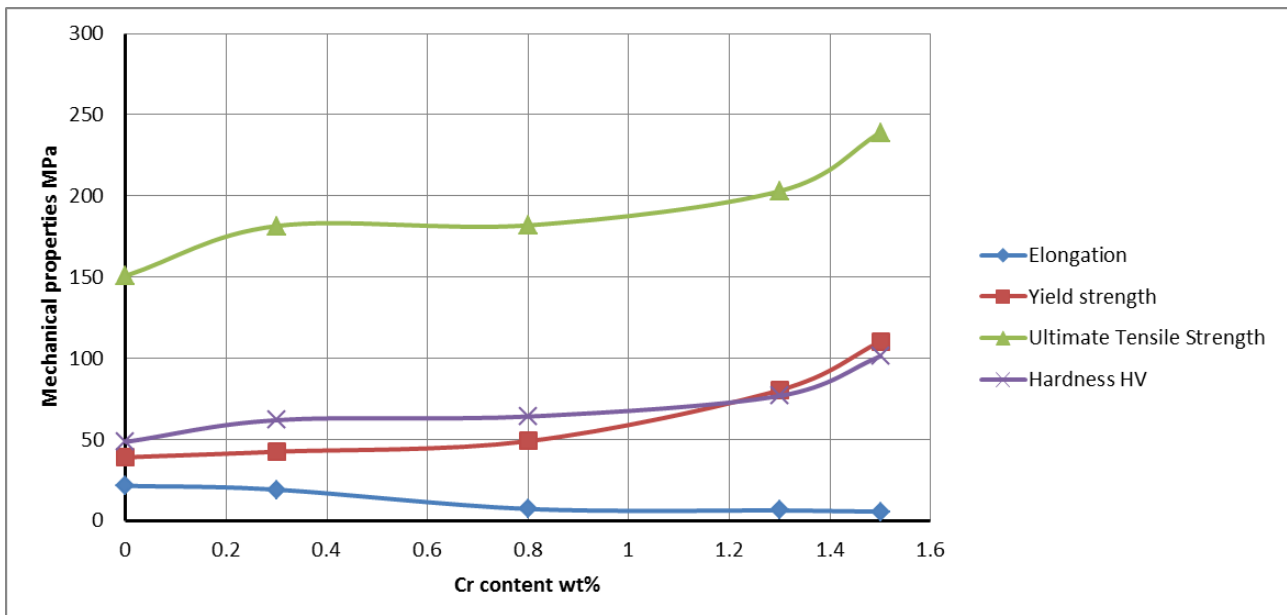

Figure 11: .Effected of $\mathrm{Cr}$ additive on the mechanical properties of $\mathrm{Cu} \mathrm{Cr}$ alloy that solution treatment in $980^{\circ} \mathrm{C}$ for $1 \mathrm{~h}$ and aging at $480^{\circ} \mathrm{C}$ for $4 \mathrm{~h}$ 